University for Business and Technology in Kosovo

UBT Knowledge Center

UBT International Conference

2017 UBT International Conference

Oct 28th, 9:00 AM - 10:30 AM

\title{
The presence of pesticides in certain imported vegetables in Republic of Kosovo
}

\author{
Ibrahim Hoxha \\ Haxhi Zeka University, ibrahim.hoxha6@gmail.com \\ Gafur Xhabiri \\ University of Tetova \\ Valdet Gjinovci \\ Food and Veterinary Agency, Pristina, Kosovo \\ Nexhdet Shala \\ Haxhi Zeka University \\ Eljesa Ziberi \\ University of Tetovo
}

Follow this and additional works at: https://knowledgecenter.ubt-uni.net/conference

Part of the Food Science Commons

\section{Recommended Citation}

Hoxha, Ibrahim; Xhabiri, Gafur; Gjinovci, Valdet; Shala, Nexhdet; and Ziberi, Eljesa, "The presence of pesticides in certain imported vegetables in Republic of Kosovo" (2017). UBT International Conference. 156.

https://knowledgecenter.ubt-uni.net/conference/2017/all-events/156

This Event is brought to you for free and open access by the Publication and Journals at UBT Knowledge Center. It has been accepted for inclusion in UBT International Conference by an authorized administrator of UBT Knowledge Center. For more information, please contact knowledge.center@ubt-uni.net. 


\title{
The presence of pesticides in certain imported vegetables in Republic of Kosovo
}

\author{
Ibrahim Hoxha ${ }^{1}$, Gafurr Xhabiri², Valdet Gjinovci ${ }^{3}$, \\ Nexhdet Shala ${ }^{1}$, Eljesa Ziberi ${ }^{2}$ \\ ${ }^{1}$ Faculty of Agribusiness, University",HaxhiZeka", Peja, Kosovo \\ ${ }^{2}$ Faculty of Food Technology and Nutrition, University of Tetova, Tetova, Macedonia \\ ${ }^{3}$ Food and Veterinary Agency, Prishtina, Kosovo \\ ibrahim.hoxha6@gmail.com
}

\begin{abstract}
The vegetables represent a food with high nutritional values, especially rich in vitamins, minerals and antioxidants, therefore it is recommended their daily consumption at least once up to twice rations per day. Based on this fact, it is of great importance to take into consideration the safety of consumption of vegetables for human health. Therefore, in this study one analyzed the content (presence) of pesticides in certain vegetables such are fresh tomatoes, fresh pepper, beans, fresh cucumbers and fresh carrots. The results that were obtained indicated that overall presence of pesticides in most of the vegetables that were studied, is minimal and within permitted limits, except for the fresh carrots where the presence of pesticide Phosalone, a chemical organophosphate which is used as insecticide and acaricide, is very high and is within maximal allowed limits of $0.01 \mathrm{mg} / \mathrm{kg}$, as well as the presence of pesticide Buprofezin is 0.04 $\mathrm{mg} / \mathrm{kg}$ which is much closer to the allowed maximal limit of $0.05 \mathrm{mg} / \mathrm{kg}$.
\end{abstract}

Keywords: pesticides, vegetables, fresh carrots, Phosalone.

\section{Introduction}

The production of vegetables in Kosovo represents one of the main branches of plant production, whereas in certain parts of the Dukagjini Plain, it represents the main economic activity [1].

The tomato plant adapts well in various types of soil, furthermore it prefers the soils with medium fertility up to rich in nutritional materials. It requires fresh soil, well drained, with mechanical content of sand and clay, well ventilated, with neutral $\mathrm{pH}$ to slightly acidic. The pepper represents one of the main vegetables which based on the area that is cultivated is second only to tomato. One of the main elements of the climate and environment are: air temperature (warm), soil temperature, air and soil humidity, light, ventilation, carbon gas, wind, soil, etc. [2]. The beans represent of the traditional agricultural crops which have a long tradition and it is widely used in the country.

Seen from the nutritional aspect, the vegetables are some of the richest foods with vitamins, minerals as well as with fibers. These ingredients play an important role in the health, by helping in prevention of various diseases such are diabetes, cardiac diseases, cancer, etc. The ever increasing demand for the availability and consumption of these fresh produce, along with the health aspect has led to the increase of global trade of vegetables and their high presence in the markets $[3,4,5]$.

On the other hand, the high usage of pesticides in the cultivation of plants and animal breeding leads to widespread contamination of environment, especially that of food and water. The 
pesticides are included in the cycle of circulation of materials in the biosphere and thus they get spread out. A special risk is represented by the durable pesticides. Pesticides and their metabolites in general do not remain only in the spot they are applied, but through physical (water, air) and biological (food chain) mediums they are distributed in great distances [6].

Based on this, this study aims to represent a part of the analysis of presence of pesticides in the food products, such are imported vegetables in our country, based on the level of their presence we have to pay special attention for the degree of risk that they represent for the human organism.

\section{Materials and methods}

All the samples of vegetables that were analyzed such are: fresh tomatoes (Licosperisionescualentum), fresh pepper (Capsicum annum L), beans (phaseolus vulgaris), fresh cucumbers and fresh carrots which were sampled in the border crossings of Republic of Kosovo. The analysis of the pesticides have been performed in the Agricultural Institute of Kosovo through standard method DIN EN 15662 with GC-MC. The obtained results have be adapted the conditions of quality according to the regulation [7] amended by [8]. The study was performed in the important vegetables during 2015.

\section{Results and discussions}

From fig. 1 one clearly observes that all the analyzed pesticides indicate a very low presence in the fresh tomatoes and fresh pepper compared with the limits prescribed on the regulation in force by European Union [7] amended by [8].

In fig. 2 are indicated the results of the analysis of the pesticides at fresh cucumbers and at beans. Also in this case, it is easily observed that based on the analyzed pesticides, their presence in the mentioned vegetables is much lower content compared to the limits indicated in the regulation in force in European Union. 


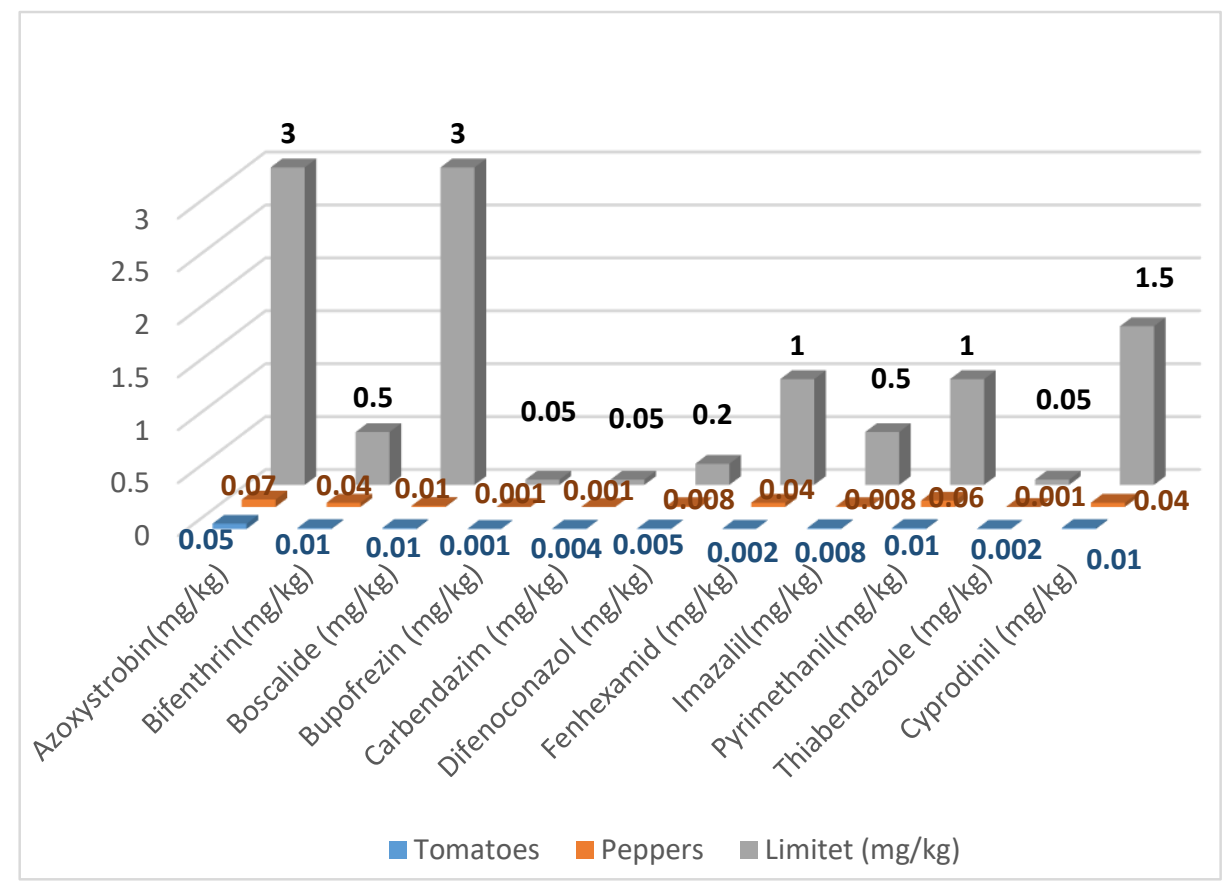

Fig. 1. The presence of pesticides in tomatoes and pepper

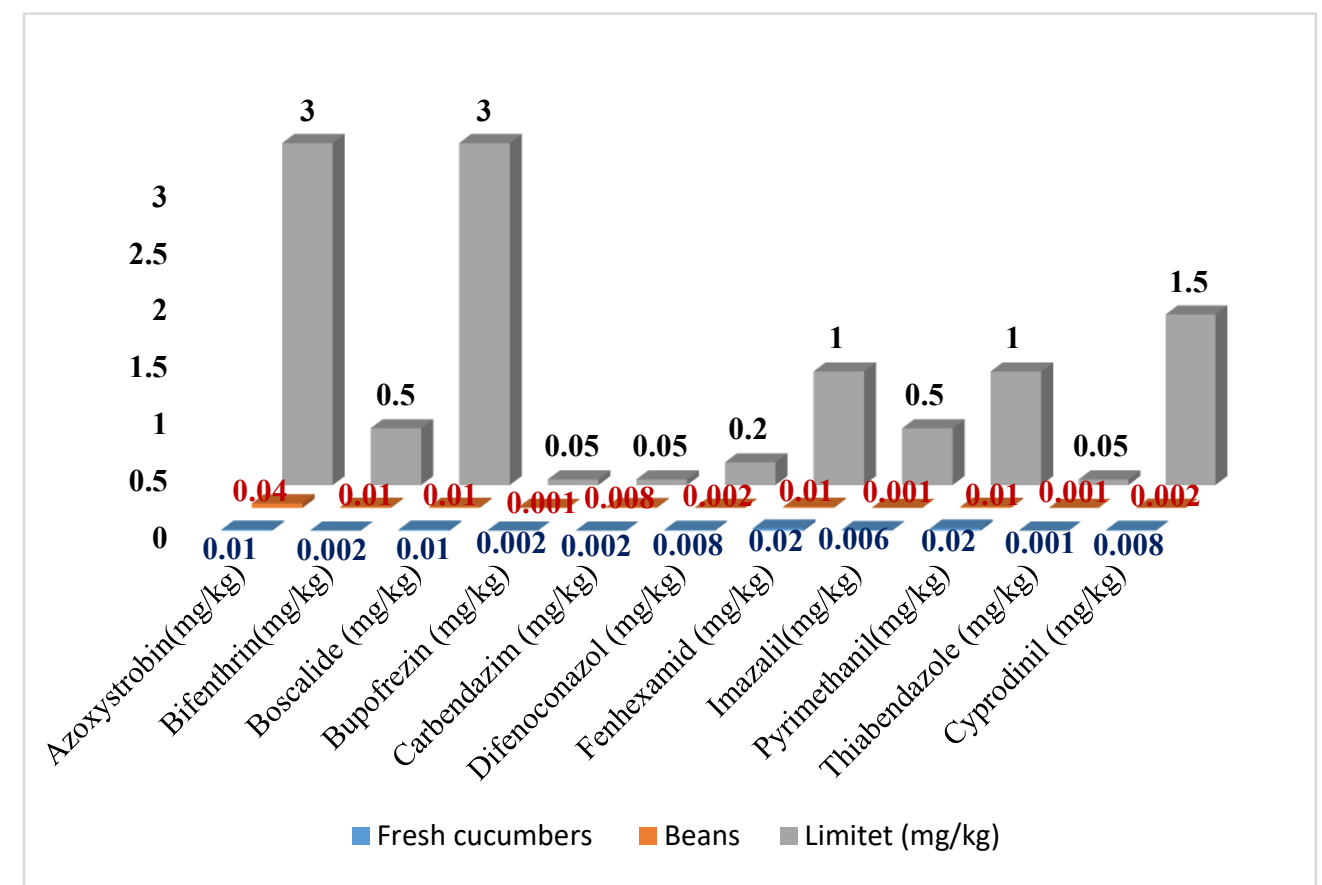

Fig. 2. The content of pesticides in the fresh cucumbers and beans 


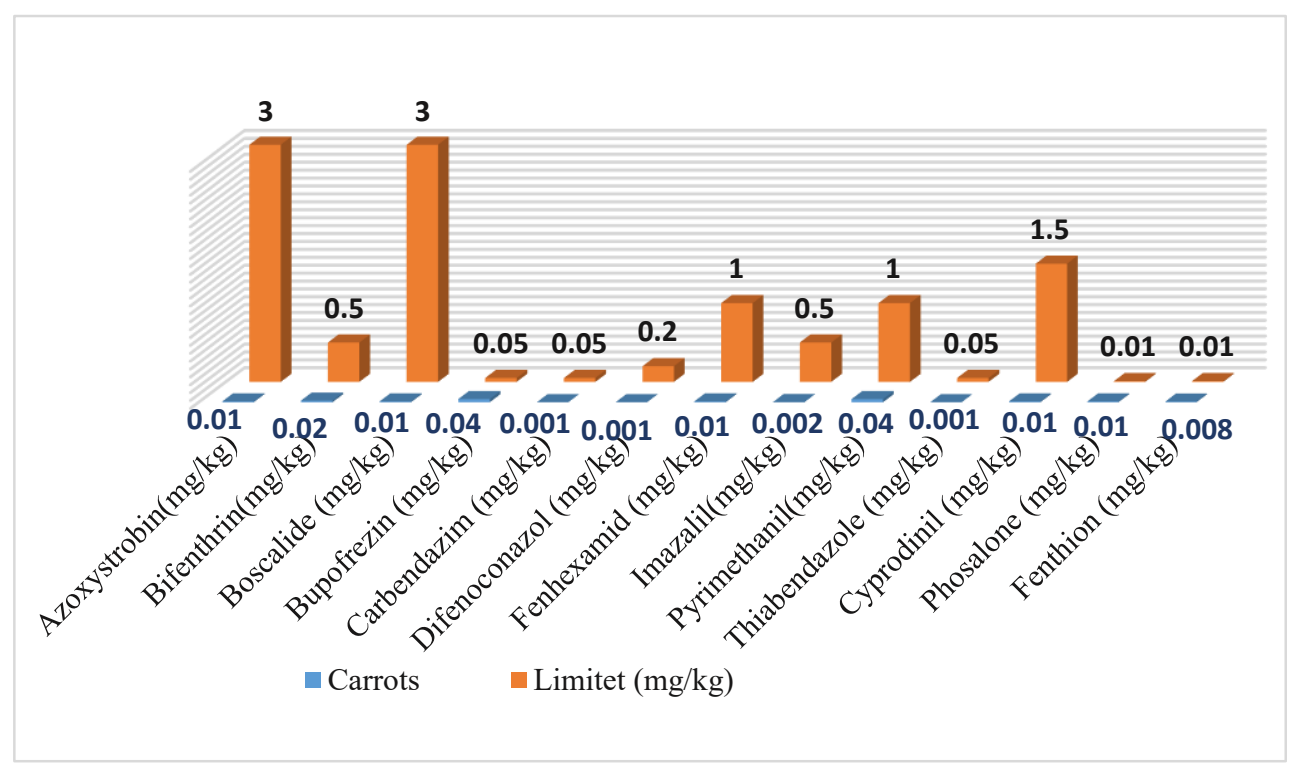

Fig 3. The presences of pesticides in carrots

In fig. 3 one depicted the content of pesticides in the imported fresh carrots. From the obtained results, one can observe that a major part of the pesticides that are used to treat the carrots are under limits stipulated by the regulations in force in European Union, more specifically in [7] and its amendment [8]. However, the content of pesticide Phosalone, which is a chemical organophosphate that is used as insecticide and acaricide, is of high level and in the maximal allowed limits of $0.01 \mathrm{mg} / \mathrm{kg}$. The organophosphate pesticides are considered as inhibitors of AChEactivity, and subsequently, accumulation of excessive acetylcholine occur in synaptic cleft available in any live organisms $[9,10,11]$.

Toxic effects of phosalone administered in the feed of rats $(0,5,50$, or $1000 \mathrm{ppm})$ were investigated by Barker and Sortwell 2016 [12] for two consecutive years, but the concentration of $1000 \mathrm{ppm}$ being reduced to $500 \mathrm{ppm}$ at week 27 . The Clinical effects such as abnormal posture, hypersensitivity, depression of AChE activity, and poor grooming were observed in groups exposed to $500 \mathrm{ppm}$ phosalone.

In addition, the presence of pesticide Buprofezin is $0.04 \mathrm{mg} / \mathrm{kg}$ which is very close to the maximal allowed limit of $0.05 \mathrm{mg} / \mathrm{kg}$. Otherwise buprofezin is an insecticide used for control of insect pests such as mealy bugs, leafhoppers and whitefly on vegetable crops. It is a growth regulator, acting as an inhibitor of chitin synthesis [13]. It is banned in some countries due to its negative environmental impacts, being especially toxic to aquatic organisms as well as non-target insects, though is of low toxicity to humans and other mammals [14].

\section{CONCLUSION}

Based on the obtained results we can conclude that the presence of the pesticides which are used to treat the imported vegetables such are fresh tomatoes, fresh pepper, beans and fresh cucumber is minimal, however the presence of some pesticides in the fresh carrots such is Phosalone is in the maximal allowed limits of $0.01 \mathrm{mg} / \mathrm{kg}$, also the presence of Buprofezin is at the maximal allowed limit of $0.05 \mathrm{mg} / \mathrm{kg}$ with content of $0.04 \mathrm{mg} / \mathrm{kg}$. 


\section{REFERENCES}

1. Vegetable growing (2011), Cooperation office MASH/DANIDA.

2. Voci Fatmir; Manual - vegetable growing on the Conditions of Protected crops and environments, 2005, Tirana.

3. Jobling, J.J., Richardson, K.C., Patterson, B.D., Freshness in convenience fruit and vegetables. Food Australia 50: 443-446, 1998.

4. Lucier, G., Leafy greens: foundation of the vegetable industry. Agricultural Outlook 248: 5-8, 1998.

5. Sloan, A.E., At the (fresh) cutting edge. Food Technology 54: 22-23, 2000.

6. Pine Oljana, Analysis of the organic pollutants in the food products and the technical modalities of gaseous chromatography, Dissertation thesis, 2017, Tirana.

7. REGULATION (EC) NO 396/2005 OF THE EUROPEAN PARLIAMENT AND OF THE COUNCIL of 23 February 2005 on maximum residue levels of pesticides in or on food and feed of plant and animal origin and amending Council Directive 91/414/EEC, Official Journal of the European Union.

8. REGULATION (EU) No 212/2013 of 11 March 2013 replacing Annex I to Regulation (EC) No 396/2005 of the European Parliament and of the Council as regards additions and modifications with respect to the products covered by that Annex, Official Journal of the European Union.

9. A. Ascherio et.al, .Pesticide Exposure and Risk for Parkinson's Disease. Annals of Neurology, 60, 2006, 197-203.

10. Colovic MB, KrsticDZ, Lazarevic-Pasti TD, Bondzic AM, VasicVM. Acetylcholinesterase Inhibitors: Pharmacology and Toxicology. CurrNeuropharmacol. 2013;11:315-325.

11. Kazemi M, Tahmasbi AM, Valizadeh R, Naserian AA, Soni A. Organophosphate pesticides: A general review. AgricSci Res J. 2012;2:512 - 22.

12. Barker MH, Sortwell RJ. Phosalone (11974 RP), Potential tumorigenic and toxic effects in prolonged dietary administration to rat. 1993. http://www.inchem. org/documents/jmpr/jmpmono/v097pr14.htm. Accessed 24 Sep 2016.

13. Liu TX, Chen TY. Effects of the chitin synthesis inhibitor buprofezin on survival and development of immatures of Chrysoperlarufilabris (Neuroptera: Chrysopidae). J Econ Entomol. 2000 Apr;93(2):234-9.

14. Qureshi IZ, Bibi A, Shahid S, Ghazanfar M. Exposure to sub-acute doses of fipronil and buprofezin in combination or alone induces biochemical, hematological, histopathological and genotoxic damage in common carp (Cyprinuscarpio L.). AquatToxicol. 2016 Oct;179:103-14. 